\title{
Which Obesity Index Best Explains the Link between Adipokines, Coronary Heart Disease Risk and Metabolic Abnormalities in Type 2 Diabetes Mellitus?
}

\author{
Olusegun A. Mojiminiyi ${ }^{a}$ Fahd Al Mulla $^{a}$ Nabila A. Abdellab \\ Departments of a Pathology and ${ }^{\mathrm{b}}$ Medicine, Faculty of Medicine, Kuwait University, Kuwait
}

\section{Key Words}

Obesity $\cdot$ Adipokines $\cdot$ Insulin resistance $\cdot$ Metabolic syndrome $\cdot$ Coronary heart disease $\cdot$ Anthropometric indices

\begin{abstract}
Objective: The aim of this study was to determine, which of: body mass index (BMI), waist-to-hip ratio (WHR), waist-toheight ratio (WHtR) and waist circumference (WC) correlates best with adipokines and is, therefore, the most suitable for the assessment of insulin resistance (IR), metabolic syndrome (MS), type 2 diabetes mellitus (T2DM) and coronary heart disease (CHD) risk. Subjects and Methods: We studied 248 T2DM patients classified by gender, IR, MS and CHD. Fasting adiponectin, leptin, resistin, high-sensitivity C-reactive protein (CRP), insulin, glucose, IR (HOMA), and lipid profile were measured. Univariate and multivariate regression analyses were used to find the associations of these variables with each other and with IR, MS and CHD. Receiver operating characteristic (ROC) analyses were used to find the best markers of IR, MS and CHD. Results: There were gender differences in the correlations and associations of BMI, WHR, WHtR and WC with IR, MS and CHD; e.g. in males, WHR showed significant correlation with only resistin $(r=0.30)$ and leptin $(r=0.39)$ whereas in females, it showed significant correlations with only adiponectin $(r=-0.33)$. In males and
\end{abstract}

females WHR showed the weakest correlations with CRP and the adipokines and BMI showed the highest correlations. ROC analysis showed that the BMI had the highest diagnostic values for detection of IR, MS and CHD; WHR had the worst diagnostic value. Conclusion: Anthropometric indices show differences in performance and associations with adipokines, CRP, IR, MS and CHD. In patients with T2DM, BMI should be the preferred marker for risk assessment on account of its association with adipokines and diagnostic performance characteristics.

Copyright $\odot 2009$ S. Karger AG, Basel

\section{Introduction}

Increasing prevalence of obesity and associated comorbidities have resulted in a pandemic of metabolic abnormalities and increased prevalence of type 2 diabetes mellitus (T2DM) and coronary heart disease (CHD) in many populations $[1,2]$. Pathways leading from obesity to development of T2DM and CHD involve a number of metabolic factors that are related to the adipose tissue mass. Adipose tissue exerts its metabolic effects via the secretion of a variety of bioactive molecules called adipokines, that include adipose tissue hormones such as adiponectin and a variety of inflammatory factors such as tumor necrosis factor- $\alpha$, interleukin-6 and resistin [3].

\section{KARGER}

Fax +4161306 1234 E-Mail karger@karger.ch www.karger.com (c) 2009 S. Karger AG, Basel

1011-7571/09/0182-0123\$26.00/0

Accessible online at:

www.karger.com/mpp
Dr. O.A. Mojiminiyi

Department of Pathology, Faculty of Medicine

Kuwait University, PO Box 24923

13110 Safat (Kuwait)

Tel. +965 531 9476, Fax +965 533 8905, E-Mail segunade@yahoo.com 
Recent research has shown that these adipokines have an impact on glucose and lipid metabolism and contribute to the metabolic syndrome (MS), which clusters insulin resistance (IR), glucose intolerance, atherogenic dyslipidemia as well as endothelial dysfunction, hypertension, prothrombotic and proinflammatory states in an individual $[4,5]$.

A growing body of literature [6-8] has shown that adipose tissue is not a single homogeneous compartment and it is the body fat distribution, rather than the total amount of adipose tissue, that leads to increased obesityassociated risks. Furthermore, although the concentrations of the adipokines are significantly related to various anthropometric measures of adiposity, there are no reports on the best anthropometric index for assessing the link between obesity, adipokines, IR and the multiple factors that confer increased risks of T2DM and CHD. We postulate that the pattern of adipose tissue distribution as reflected in various routinely used anthropometric indices is a significant determinant of the adipokines and, as a result, each index will have different associations with obesity-associated physiological and pathological processes. The aim of this study was to determine which of: body mass index (BMI), waist-to-hip ratio (WHR), waist-to-height ratio and waist circumference (WC) is most closely related to the adipokines. As there are gender differences in the pattern of fat distribution, an additional aim was to examine probable gender-dependent differences in the associations between anthropometric indices and IR, MS and CHD in patients with T2DM.

\section{Subjects and Methods}

\section{Patients and Clinical Features}

Two hundred and forty-eight patients (109 males and $139 \mathrm{fe}-$ males) referred to the specialized Diabetes Clinic (after diagnosis in primary care clinics) at the Mubarak Al Kabir Hospital were eligible to take part in this study. Patients were on treatment with oral hypoglycemic agents but none was on insulin or insulin-sensitizing drugs (thiazolidinedione compounds) or lipid-lowering medication at the time of recruitment for the study. At the time of the study, 125 females were known to be menopausal. The study protocol and procedures were approved by the Institution's Ethics Committee and, in accordance with the ethical standards of the Helsinki Declaration, all participants gave informed consent for their participation. After providing informed consent, fasting blood samples were collected from all patients during (if fasting) or after the first visit to the Diabetes Clinic. Exclusion criteria were: refusal to take part in the study, intercurrent illness or clinically evident infections, overt clinical or laboratory evidence of connective tissue diseases or hemoglobinopathies.
All anthropometric measurements were made by trained observers using standard techniques [9] with the participant wearing light clothes without shoes. Height (to the nearest $0.1 \mathrm{~cm}$ ) was determined by use of a stadiometer, and weight (to the nearest $0.1 \mathrm{~kg}$ ) was determined by use of a standardized standing beam balance. Waist circumference was measured midway between the lowest rib and the iliac crest with the subject standing at the end of gentle expiration, and the hip circumference at the level of the widest diameter around the gluteal protuberance.

The subjects were interviewed by a trained nurse who completed a questionnaire on age, smoking status, history of hypertension and/or antihypertensive medication and symptoms of cardiovascular disease. Patients were classified into those with $\mathrm{CHD}$ and without $\mathrm{CHD}$ based on the presence or absence of: resting electrocardiographic (ECG) abnormalities consistent with CHD; ECG was coded using the Minnesota code [10] and CHD was defined as probable ischemia (code 1.1-1.2) or possible ischemia (code 1.3, 4.1-4.4, 5.1-5.3, or 7.1), history of myocardial infarction or angina (evaluated with the Rose [11] questionnaire) with a positive exercise tolerance test, or angiographically proven coronary artery disease.

Systolic blood pressure and diastolic blood pressure were measured using a mercury column sphygmomanometer and a cuff suitable to the subject's arm circumference. Blood pressure was measured twice after 5 min of rest in the sitting position, and the average of the measurements was recorded. Hypertension was defined as active treatment with any antihypertensive agent or mean systolic blood pressure $\geq 140 \mathrm{~mm} \mathrm{Hg}$ or diastolic blood pressure $\geq 90 \mathrm{~mm} \mathrm{Hg}$ [12]

\section{Laboratory Methods}

Adipokines. Fasting plasma adiponectin (Linco Research, St. Charles, Mo., USA), leptin (Diagnostics Systems Laboratories, Webster, Tex., USA), and resistin (BioVendor, Brno, Czech Republic) were measured using commercially available enzyme-linked immunoassay (ELISA) kits. The inter- and intra-assay coefficients of variation on pooled plasma specimens were 4.7 and $6.8 \%$, respectively, for adiponectin (concentration of $8.2 \mu \mathrm{g} / \mathrm{ml}$ ); 4.1 and $5.3 \%$, respectively, for leptin (concentration of $23.6 \mathrm{ng} / \mathrm{ml}$ ), and 3.1 and $4.8 \%$, respectively, for resistin (concentration of $24.2 \mathrm{ng} /$ $\mathrm{ml}$ ). The concentration of C-reactive protein (CRP) was determined with a high-sensitivity chemiluminescent assay on the Immulite (DPC, Los Angeles, Calif., USA). The assay has a lower limit of detection of $0.1 \mathrm{mg} / \mathrm{l}$. The intra- and interassay coefficients of variation for CRP (pooled serum concentration $1.5 \mathrm{mg} / \mathrm{l}$ ) were 5.3 and $6.0 \%$, respectively.

Other Assays. Fasting plasma glucose, total cholesterol, triglycerides (TG), high density lipoprotein cholesterol (HDL-C), apolipoprotein A1 (Apo-A1), apolipoprotein B (Apo B) and creatinine were analyzed on an automated analyzer (Beckman LX20, Beckman Corp., Brea, Calif., USA). The low density lipoprotein cholesterol (LDL-C) was calculated using the formula of Friedewald et al. [13]. Fasting serum insulin was determined by an ELISA (DSL-10-1600 ACTIVE, Diagnostics Systems Laboratories, Tex., USA). IR was calculated using the homeostasis model assessment (HOMA-R) formula using a calculator downloaded from http://www.dtu.ox.ac.uk/index.html?maindoc=/publications/ [14]. The HOMA calculator also gives estimates of steadystate beta cell function and insulin sensitivity. As both glucose and insulin levels are measured, the HOMA calculation has been 
shown to give good correlation with non-steady-state estimates of beta cell function and insulin sensitivity derived from stimulatory models such as the hyperinsulinemic clamp [15]. The lower limit of the top quintile of HOMA-R distribution (i.e., 2.0) in apparently healthy nonobese $\left(\mathrm{BMI}<25 \mathrm{~kg} / \mathrm{m}^{2}\right)$ Kuwaiti subjects was used as the cutoff for defining IR [16]. The number of features of MS based on the International Diabetes Federation criteria [4] was recorded. The patients were then classified as MS-positive if they met the criteria or MS-negative if they did not.

\section{Statistical Analyses}

Statistical Package for the Social Sciences (SPSS), version 14.0 for Windows software (SPSS Inc., Chicago, Ill., USA), was used for statistical analysis and $\mathrm{p}<0.05$ was considered statistically

Table 1. Anthropometric indices and adipokines in the patients grouped by gender

\begin{tabular}{lccl}
\hline Parameter & Male & Female & $\mathrm{p}$ \\
\hline Age, years & $58.8(11.6)$ & $58.9(10.1)$ & $\mathrm{NS}$ \\
BMI & $30.4(5.2)$ & $31.8(6.0)$ & $\mathrm{NS}$ \\
Waist, cm & $106.7(12.4)$ & $105.2(12.9)$ & $\mathrm{NS}$ \\
WHR & $1.03(0.07)$ & $0.99(0.10)$ & 0.002 \\
Hip, cm & $103.8(9.3)$ & $106.8(11.7)$ & $\mathrm{NS}$ \\
WHtR & $0.64(0.08)$ & $0.68(0.09)$ & 0.001 \\
HDL-C, mmol/l & $1.14(0.31)$ & $1.23(0.28)$ & 0.003 \\
Insulin, $\mu$ IU/ml & $18.6(13.4)$ & $23.2(18.1)$ & $\mathrm{NS}$ \\
HOMA-R & $2.53(1.40)$ & $2.30(1.13)$ & $\mathrm{NS}$ \\
Beta cell function, \% & $77.4(96.6)$ & $51.7(39.1)$ & $\mathrm{NS}$ \\
Insulin sensitivity, \% & $52.8(30)$ & $59.9(35.4)$ & $\mathrm{NS}$ \\
Resistin, ng/ml & $22.0(9.2)$ & $24.7(10.6)$ & $\mathrm{NS}$ \\
Adiponectin, $\mu \mathrm{g} / \mathrm{ml}$ & $7.2(3.7)$ & $7.9(3.5)$ & $\mathrm{NS}$ \\
Leptin, ng/ml & $23.8(19.2)$ & $46.3(22.4)$ & $<0.0001$ \\
hs-CRP, mg/l & $0.51(0.51)$ & $1.04(1.10)$ & $<0.0001$ \\
Smokers, \% & 29.3 & 10.8 & $<0.0001$ \\
\hline
\end{tabular}

WHtR = Waist-to-height ratio. Values are mean (standard deviation in parentheses) except for smoking status; $p$ values are differences between males and females. significant for all analyses. Data are presented as mean and standard deviation. Several variables - BMI, WHR, adiponectin, leptin, high-sensitivity (hs)-CRP, TG, insulin, beta cell function, insulin sensitivity and HOMA-R - were not normally distributed. These variables were log-transformed when parametric tests were used. Spearman correlation coefficients (r) were used to describe the association between variables and comparison between two groups was performed with the Mann-Whitney U test. The Kruskal-Wallis analysis of variance was used to compare between more than two groups and categorical variables were compared with $\chi^{2}$ test. Multivariate logistic regression analysis was performed to assess the main anthropometric determinants of adiponectin, resistin, leptin and hs-CRP after correcting for the confounding effects of age.

To assess the diagnostic accuracy of the anthropometric indices in predicting IR, MS and CHD, receiver operating characteristic (ROC) plots [17] were performed. The area under the curve and $95 \%$ confidence interval were calculated for each plot.

\section{Results}

\section{General Results}

Of the 109 males, 56 (51\%) and of the 139 females, 67 (48\%) had HOMA-R $>2$ while 70 (64\%) of males and 72 (52\%) of females were MS-positive. Forty-seven (43\%) males and 49 (35\%) females had CHD. The summary of the data in the patients grouped by gender is shown in table 1 . In view of the gender differences in some of the variables, further data analyses were performed separately in males and females.

\section{Correlations of Anthropometric Indices}

The correlations between the anthropometric indices and other variables are given in table 2. In males and females WHR showed the weakest correlations with CRP and the adipokines and BMI showed the highest correlations. There are significant gender differences in the correlations of adipokines with anthropometric in-

Table 2. Spearman rank correlations between anthropometric indices, adipokines, insulin and IR

\begin{tabular}{|c|c|c|c|c|c|c|c|c|c|c|c|c|}
\hline & \multicolumn{2}{|c|}{ Adiponectin } & \multicolumn{2}{|l|}{ Resistin } & \multicolumn{2}{|l|}{ Leptin } & \multicolumn{2}{|c|}{ Insulin } & \multicolumn{2}{|c|}{ HOMA-R } & \multicolumn{2}{|l|}{ hs-CRP } \\
\hline & males & females & males & females & males & females & males & females & males & females & males & females \\
\hline Weight, kg & $-0.37^{* *}$ & $-0.26^{*}$ & $0.56^{* * *}$ & $0.62^{* * *}$ & $0.42^{* * *}$ & $0.64^{* * *}$ & $0.27^{*}$ & $0.51^{* * *}$ & $0.264^{*}$ & $0.34^{* *}$ & $0.40^{* *}$ & $0.45^{* * *}$ \\
\hline BMI & $-0.38^{* *}$ & $-0.30^{* *}$ & $0.61^{* * *}$ & $0.67^{* * *}$ & $0.54^{* * *}$ & $0.62^{* * *}$ & $0.29^{*}$ & $0.55^{* * *}$ & $0.28^{*}$ & $0.37^{* *}$ & $0.49^{* * *}$ & $0.49^{* * *}$ \\
\hline Waist, cm & $-0.46^{* * *}$ & $-0.25^{*}$ & $0.61^{* * *}$ & $0.48^{* * *}$ & $0.54^{* * *}$ & $0.58^{* * *}$ & $0.30^{*}$ & $0.46^{* * *}$ & 0.16 & $0.27^{*}$ & $0.45^{* *}$ & $0.27^{*}$ \\
\hline WHR & -0.23 & $-0.33^{* *}$ & $0.30^{*}$ & 0.01 & $0.39^{* *}$ & -0.08 & 0.16 & 0.05 & -0.06 & 0.07 & 0.19 & -0.08 \\
\hline Hip, cm & $-0.41^{* *}$ & 0.03 & $0.54^{* * *}$ & $0.43^{* * *}$ & $0.46^{* * *}$ & $0.64^{* * *}$ & $0.31^{*}$ & $0.37^{* *}$ & $0.25^{*}$ & $0.25^{*}$ & $0.47^{* * *}$ & $0.39^{* *}$ \\
\hline WHtR & $-0.39 * *$ & $-0.30^{*}$ & $0.53^{* * *}$ & $0.44^{* * *}$ & $0.55^{* * *}$ & $0.47^{* * *}$ & $0.38^{*}$ & $0.42^{* * *}$ & 0.22 & 0.19 & $0.41^{* *}$ & $0.24^{*}$ \\
\hline
\end{tabular}

WHtR $=$ Waist-to-height ratio. Values are correlation coefficients. ${ }^{*} \mathrm{p}<0.05 ;{ }^{* *} \mathrm{p}<0.01 ;{ }^{* * *} \mathrm{p}<0.001 ;$ no asterisk: $\mathrm{p}>0.05$. 


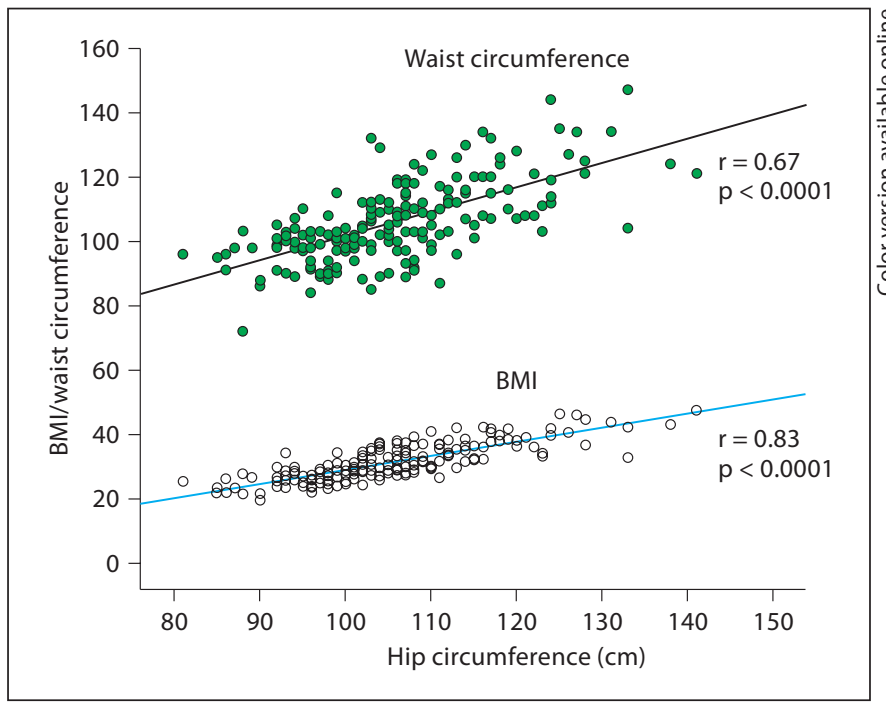

Fig. 1. Scatterplot showing the relationship between hip circumference (x axis) and BMI (y axis, lower scatter points) and waist circumference (y axis, upper scatter points). Lines through the scatter points are regression-based fit lines showing the trend of the data. dices and IR, e.g. in males, WHR showed significant correlation with only resistin and leptin, whereas in females it showed significant correlations with only adiponectin. Similarly, WC was significantly correlated with insulin but not HOMA-R in males, whereas it was significantly correlated with both parameters in females. The hip circumference increases with increasing BMI and WC (fig. 1) and correlates negatively with adiponectin and positively with resistin, leptin and insulin (table 2).

\section{Correlations of Anthropometric Indices with Lipid Parameters}

The correlations of lipid parameters with anthropometric indices are shown in table 3. In males, BMI showed significant correlations with HDL-C (negative correlation) and TG (positive correlation), but in females there were no significant correlations with these indices that are included in the definitions of MS.

Table 3. Spearman rank correlations of anthropometric indices with lipid parameters

\begin{tabular}{|c|c|c|c|c|c|c|c|c|c|c|c|c|}
\hline & \multicolumn{2}{|c|}{ HDL-C, mmol/l } & \multicolumn{2}{|c|}{$\mathrm{TG}, \mathrm{mmol} / \mathrm{l}$} & \multicolumn{2}{|c|}{$\begin{array}{l}\text { Total choles- } \\
\text { terol, } \mathrm{mmol} / \mathrm{l}\end{array}$} & \multicolumn{2}{|c|}{ LDL-C, mmol/l } & \multicolumn{2}{|c|}{ Apo-A1, g/l } & \multicolumn{2}{|c|}{ Apo B, g/l } \\
\hline & males & females & males & females & males & females & males & females & males & females & males & females \\
\hline Weight, kg & $-0.28^{* *}$ & -0.09 & $0.31^{* *}$ & 0.08 & 0.06 & -0.06 & 0.05 & -0.08 & -0.19 & -0.06 & 0.19 & 0.01 \\
\hline BMI & $-0.23^{*}$ & -0.02 & $0.26^{*}$ & 0.05 & 0.09 & 0.01 & 0.05 & -0.01 & -0.05 & -0.04 & $0.28^{* *}$ & 0.05 \\
\hline Waist, cm & -0.10 & -0.17 & 0.21 & 0.08 & 0.12 & 0.02 & 0.10 & 0.02 & 0.01 & -0.11 & $0.27^{*}$ & 0.09 \\
\hline WHR & -0.17 & 0.03 & $0.29^{* *}$ & -0.02 & 0.15 & -0.09 & 0.15 & -0.11 & -0.09 & -0.004 & $0.38^{* * *}$ & -0.08 \\
\hline Hip, cm & 0.07 & -0.17 & 0.04 & 0.18 & 0.04 & 0.06 & -0.02 & 0.04 & $0.23^{*}$ & -0.03 & 0.04 & 0.15 \\
\hline WHtR & -0.01 & -0.15 & 0.12 & 0.09 & 0.056 & 0.01 & -0.02 & 0.01 & 0.19 & -0.08 & 0.20 & 0.07 \\
\hline
\end{tabular}

Values are correlation coefficients. ${ }^{*} \mathrm{p}<0.05 ;{ }^{* *} \mathrm{p}<0.01 ;{ }^{* * *} \mathrm{p}<0.001$; no asterisk: $\mathrm{p}>0.05$.

Table 4. Multivariate regression analysis using resistin and log-transformed values of adiponectin, leptin, hs-CRP, HOMA-R adiponectin as dependent variables and anthropometric variables as independent variables

\begin{tabular}{llllll}
\hline & \multicolumn{2}{l}{ Adiponectin } & & \multicolumn{2}{l}{ Resistin } \\
\cline { 2 - 3 } \cline { 5 - 6 } & males & females & & males & females \\
\hline Weight, $\mathrm{kg}$ & $-0.41(-0.27 \text { to }-0.09)^{* *}$ & $-0.31(-0.21 \text { to }-0.04)^{* *}$ & & $0.52(0.17 \text { to } 0.47)^{* * *}$ & $0.62(0.30 \text { to } 0.53)^{* * *}$ \\
BMI & $-0.28(-0.50 \text { to }-0.10)^{* * *}$ & $-0.22(-0.35 \text { to }-0.06)^{* *}$ & & $0.41(0.30 \text { to } 0.76)^{* * *}$ & $0.51(0.50 \text { to } 0.89)^{* * *}$ \\
Waist, cm & $-0.35(-0.26 \text { to }-0.086)^{* * *}$ & $-0.18(-0.16 \text { to }-0.05)^{*}$ & & $0.42(0.15 \text { to } 0.35)^{* * *}$ & $0.32(0.11 \text { to } 0.33)^{* * *}$ \\
WHR & $-0.14(-29.06$ to 4.01$)$ & $-0.81(-20.48 \text { to }-0.97)^{*}$ & & $0.25(6.75 \text { to } 45.73)^{* *}$ & $0.03(-12.26$ to 17.31$)$ \\
Hip, cm & $-0.46(-0.59 \text { to }-0.17)^{* *}$ & $-0.06(-0.14$ to 0.08$)$ & & $0.52(0.28 \text { to } 0.80)^{* * *}$ & $0.47(0.23 \text { to } 0.61)^{* * *}$ \\
WHtR & $-0.28(-37.49$ to -7.51$)$ & $-0.17(-23.53 \text { to }-0.47)^{*}$ & & $0.43(25.39 \text { to } 59.22)^{* * *}$ & $0.30(14.95 \text { to } 48.22)^{* * *}$ \\
\hline
\end{tabular}

WHtR $=$ Waist-to-height ratio. ${ }^{*} \mathrm{p}<0.05 ;{ }^{* *} \mathrm{p}<0.01 ;{ }^{* * *} \mathrm{p}<0.001$; no asterisk: $\mathrm{p}>0.05$. 


\section{Regression Analyses}

The multivariate regression analysis using resistin and log-transformed values of adiponectin, leptin, hs-CRP, HOMA-R adiponectin as dependent variables and anthropometric variables as independent variables are shown in table 4 . The anthropometric indices were main determinants of most of the adipokines although there are gender differences in the associations with HOMA-R. Body weight proved to be a significant determinant of IR and adipokines in females, but no association was found with IR in males.

\section{ROC Analyses}

Comparison of areas under the ROC curve showed that the BMI had the highest diagnostic values for detection of IR, MS and CHD, and WHR had the worst overall performance characteristics (table 5).

\section{Discussion}

In routine practice, obesity is assessed with several anthropometric indices each of which has advantages and disadvantages and produces different results when used to assess the link between obesity, IR, MS and CHD. In this study, we confirmed that anthropometric indices showed different and variable associations with adipokines, IR, MS and CHD in patients with T2DM. We also found that despite similar anthropometric indices, males and females had significant differences in the associations with adipokines and lipid parameters.

The differences in the associations of anthropometric indices with IR, MS and CHD are not surprising because the indices reflect different aspects of obesity and adipose tissue distribution such as whether fat distribution is subcutaneous, visceral, generalized, total or regional. The pattern of fat distribution is important because there are metabolic differences between different fat depots and, as a result, differences are expected in their clinical usefulness as predictors of metabolic disturbances and associated diseases [6-8]. Consequently, the secretion of adipokines differs greatly among adipose tissue deposits based on the pattern of body fat distribution rather than total fat burden [18]. Although the mechanisms are poorly understood, having a lot of peripheral fat mass appears to improve insulin sensitivity and counteract the atherogenic effects of central fat mass [19-21]. Therefore, in our study, the regional variations in adipokine production by adipose tissue may, in part, be accountable for the differences in the associations between anthropometric indices, IR, MS and CHD.

Although the WHR has been found to be useful in predicting IR, MS and CHD in several populations [2225], it was poorly correlated with other anthropometric indices in this study and has the worst overall performance characteristics on ROC analysis (table 5). This may be due, in part, to the fact that we found that hip circumference was associated with factors that increase the risk of IR, MS and CHD. The negative correlation of hip circumference with adiponectin and positive associations with resistin, leptin and hs-CRP (tables 2, 4) mean that the protective role of peripheral fat tissue and muscle mass at the hips [26-28] was certainly not found in our cohort. Therefore, our results on WHR may be due to the fact that hip circumference increased in direct proportion to increase in BMI and WC (fig. 1) and showed significant correlations with variables that are associated with IR and CHD (tables 2, 4; fig. 1). As waist and hip circumferences measure different patterns of body fat distribution, which have independent effects on adipokines and CHD risk factors, the specific effects of each measure may be poorly captured in the WHR.

\begin{tabular}{|c|c|c|c|c|c|}
\hline \multicolumn{2}{|l|}{ Leptin } & \multicolumn{2}{|l|}{ HOMA-R } & \multicolumn{2}{|l|}{ hs-CRP } \\
\hline $0.43(0.77 \text { to } 1.78)^{* * *}$ & $0.49(1.04 \text { to } 1.91)^{* * *}$ & $0.14(-0.01$ to 0.06$)$ & $0.23(0.01 \text { to } 0.05)^{* *}$ & $0.30(0.01 \text { to } 0.04)^{* *}$ & $0.28(0.02 \text { to } 0.06)^{* *}$ \\
\hline $0.39(0.29 \text { to } 0.77)^{* * *}$ & $0.37(0.33 \text { to } 0.80)^{* * *}$ & 0.09 (-0.01 to 0.02$)$ & $0.19(0.0 \text { to } 0.02)^{*}$ & $0.33(0.01 \text { to } 0.02)^{* * *}$ & 0.13 (-0.00 to 0.02$)$ \\
\hline $0.32(33.08 \text { to } 119.89)^{* *}$ & $-0.025(-37.7$ to 28.04$)$ & $0.02(-2.40$ to 2.93$)$ & $0.03(-1.40$ to 1.45$)$ & $0.16(-0.19$ to 2.11$)$ & $-0.10(-2.48$ to 0.65$)$ \\
\hline
\end{tabular}


Table 5. Areas under the ROC curves

\begin{tabular}{|c|c|c|c|c|c|c|}
\hline & \multicolumn{2}{|l|}{$\mathrm{CHD}$} & \multicolumn{2}{|l|}{ MS } & \multicolumn{2}{|l|}{ HOMA-R >2 } \\
\hline & males & females & males & females & males & females \\
\hline Weight, kg & $0.35(0.06)^{*}$ & $0.41(0.06)$ & $0.68(0.08)^{*}$ & $0.60(0.06)$ & $0.71(0.09)^{*}$ & $0.68(0.07)^{*}$ \\
\hline BMI & $0.57(0.06)^{* *}$ & $0.53(0.06)^{*}$ & $0.70(0.08)^{* *}$ & $0.63(0.06)^{*}$ & $0.72(0.09)^{*}$ & $0.70(0.07)^{* *}$ \\
\hline Waist, $\mathrm{cm}$ & $0.44(0.06)$ & $0.53(0.05)$ & $0.76(0.08)^{* *}$ & $0.74(0.006)^{* * *}$ & $0.62(0.10)$ & $0.61(0.08)$ \\
\hline WHR & $0.56(0.06)$ & $0.62(0.05)$ & $0.69(0.08)^{*}$ & $0.71(0.06)^{* *}$ & $0.46(0.10)$ & $0.49(0.08)$ \\
\hline Hip, cm & $0.37(0.06)^{*}$ & $0.41(0.06)$ & $0.66(0.08)^{*}$ & $0.65(0.08)$ & $0.71(0.09)^{*}$ & $0.65(0.08)$ \\
\hline WHtR & $0.48(0.06)$ & $0.57(0.06)$ & $0.72(0.08)^{* *}$ & $0.74(0.06)^{* * *}$ & $0.69(0.10)$ & $0.59(0.08)$ \\
\hline
\end{tabular}

Values are areas under the ROC curves (standard error in parentheses). WHtR $=$ Waist-to-height ratio. ${ }^{*} \mathrm{p}<0.05 ;{ }^{* *} \mathrm{p}<0.01$; ${ }^{* * *} \mathrm{p}<0.001$; no asterisk: $\mathrm{p}>0.05$.

We have also found that gender is another important factor that affects the associations between adipokines and IR, MS and CHD. The gender differences may be related to the fact that endogenous androgen and estradiol metabolism, which are related to body fat distribution, significantly affect adipokine secretion from adipocytes $[29,30]$. Reports have shown that high plasma levels of bioavailable estradiol predict IR independent of the degree of obesity and the plasma estradiol concentration is independently and negatively associated with adiponectin with direct implications for the degree of IR [31] The gender differences in the associations between lipid parameters, adipokines and anthropometric indices (tables 2,3) confirm the need to have gender-based cutoff points for defining the risks associated with obesity.

Our data suggest that the BMI is the best overall marker for risk assessment in patients with T2DM, although WC could also be used since its correlations with the adipokines and performance characteristics are similar to those of the BMI (tables 2, 4, 5). In this regard, our findings are somewhat different from studies that showed that measures of abdominal fat are better predictors of $\mathrm{CHD}$ and diabetes mellitus than total adiposity as assessed by the BMI [22, 32-34]. Therefore, in recent years, there has been more focus on the use of WC for risk assessment and a recent commentary [35] on the INTERHEART study [22] concluded that the BMI is obsolete. This conclusion is not supported by our results, which suggest that, in patients with T2DM, BMI should be the preferred marker of obesity-associated risks.

There are some limitations to this study that should be considered in the interpretation of our data. Due to the relatively high prevalence of T2DM in the Kuwaiti population [36] and for logistic reasons, we were unable to re- cruit sufficient numbers of age- and sex-matched nondiabetic controls in this study. Therefore, our results must be interpreted with caution in extrapolating our findings to the general nondiabetic population in whom prospective epidemiological studies are required to confirm our observations.

\section{Conclusion}

Anthropometric indices vary in their associations with adipokines, IR, MS and CHD but the BMI, which has traditionally been used as a marker of obesity, has the best correlations and WHR the worst correlations with adipokines. Therefore, BMI may be the preferred marker for identifying the link between adiposity, IR, MS and CHD in patients with T2DM.

\section{Acknowledgments}

This project was funded in part by Kuwait Foundation for the Advancement of Science (KFAS) grant No. 2004-1302-03. We thank Dr. Sunila George, Mrs. Cynthia Pinto, Mrs. Reema Matthews and Tahani Al Rammah for technical assistance.

References

1 Zimmet P, Alberti KG, Shaw J: Global and societal implications of the diabetes epidemic. Nature 2001;414:782-787.

$\checkmark 2$ Abdella NA: Controversies in management of diabetes in patients with coronary heart disease. Med Princ Pract 2002;11:69-74.

$\checkmark 3$ Berg AH, Scherer PE: Adipose tissue, inflammation, and cardiovascular disease. Circ Res 2005;96:939-949. 
4 International Diabetes Federation: The IDF consensus worldwide definition of the metabolic syndrome. http://www.idf.org/ webdata/docs/MetSyndrome_FINAL.pdf (accessed April 2007).

$\checkmark 5$ Eckel RH, Grundy SM, Zimmet PZ: The metabolic syndrome. Lancet 2005;365:14151428.

66 Shen W, Wang Z, Punyanyita M, Lei J, Sinav A, Kral JG, Imielinska C, Ross R, Heymsfield $\mathrm{SB}$ : Adipose tissue quantification by imaging methods: a proposed classification. Obes Res 2003;11:5-16

$\checkmark 7$ Fain JN, Madan AK, Hiler ML, Cheema P, Bahouth SW: Comparison of the release of adipokines by adipose tissue, adipose tissue matrix, and adipocytes from visceral and subcutaneous abdominal adipose tissues of obese humans. Endocrinology 2004; 145: 2273-2282.

$\checkmark 8$ Karelis AD, St-Pierre DH, Conus F, RabasaLhoret R, Poehlman ET: Metabolic and body composition factors in subgroups of obesity: what do we know? J Clin Endocrinol Metab 2004;89:2569-2575.

9 World Health Organisation: Measuring Obesity: Classification and Distribution of Anthropometric Data. Nutr UD, EUR/ICP/ NUT 125. Copenhagen, WHO, 1989.

10 Blackburn H: Electrocardiographic classification for population comparisons: the Minnesota code. J Electrocardiol 1969;52:5-9.

11 Rose GA: The diagnosis of 'ischaemic' heart pain and intermittent claudication in field surveys. Bull World Health Organ 1962;27: 645-658.

12 Chobanian AV, Bakris GL, Black HR, Cushman WC, Green LA, Izzo JL Jr, Jones DW, Materson BJ, Oparil S, Wright JT Jr, Roccella EJ: The Seventh Report of the Joint National Committee on Prevention, Detection, Evaluation, and Treatment of High Blood Pressure: the JNC 7 report. JAMA 2003;289: 2560-2572.

$\checkmark 13$ Friedewald WT, Levy RT, Fredrickson DS: Estimation of the concentration of low density lipoprotein cholesterol in plasma without use of the ultracentrifuge. Clin Chem 1972;18:449-502.

14 Diabetes Trials Unit, Oxford, URL. HOMA Calculator v2.2. http://www.dtu.ox.ac.uk/ index.html?maindoc=/publications/ (accessed September 2007).

-15 Bonora E, Targher G, Alberiche M, Bonadonna RC, Saggiani F, Zenere MB, Monauni T, Muggeo M: Homeostasis model assessment closely mirrors the glucose clamp technique in the assessment of insulin sensitivity: studies in subjects with various degrees of glucose tolerance and insulin sensitivity. Diabetes Care 2000;23:57-63.
6 Bonora E, Kiechl S, Willeit J, Oberhollenzer F, Egger G, Targher G, Alberiche M, Bonadonna RC, Muggeo M: Prevalence of insulin resistance in metabolic disorders. The Bruneck Study. Diabetes 1998;47:16431649.

17 Zweig MH, Campbell G: Receiver-operating characteristic (ROC) plots: a fundamental evaluation tool in clinical medicine. Clin Chem 1993;39:561-577.

18 Schäffler A, Scholmerich J, Buchler C: Mechanisms of disease: adipocytokines and visceral adipose tissue - emerging role in intestinal and mesenteric diseases. Nat Clin Pract Gastroenterol Hepatol 2005;2:103-111.

19 Tanko LB, Bruun JM, Alexandersen P, Bagger YZ, Richelsen B, Christiansen C, Larsen PJ: Novel associations between bioavailable estradiol and adipokines in elderly women with different phenotypes of obesity: implications for atherogenesis. Circulation 2004 110:2246-2252.

20 Tankó LB, Bagger YZ, Alexandersen P, Larsen PJ, Christiansen C: Peripheral fat mass exhibits an independent dominant antiatherosclerotic effect in elderly women. Circulation 2003;107:1626-1631.

21 Snijder MB, Dekker JM, Visser M, Bouter LM, Stehouwer CD, Kostense PJ, Yudkin JS Heine RJ, Nijpels G, Seidell JC: Associations of hip and thigh circumferences independent of waist circumference with the incidence of type 2 diabetes: the Hoorn Study. Am J Clin Nutr 2003;77:1192-1197

22 Yusuf S, Hawken S, Ounpuu S, Bautista L, Franzosi MG, Commerford P, Lang CC, Rumboldt Z, Onen CL, Lisheng L, Tanomsup S, Wangai P Jr, Razak F, Sharma AM, Anand SS: Obesity and the risk of myocardial infarction in 27,000 participants from 52 countries: a case-control study. Lancet 2005 366:1640-1649.

-23 Larsson B, Svärdsudd K, Welin L, Wilhelmsen L, Björntorp P, Tibblin G: Abdominal adipose tissue distribution, obesity, and risk of cardiovascular disease and death: 13 year follow-up of participants in the study of men born in 1913. BMJ 1984;288:1401-1404.

24 Lapidus L, Bengtsson C, Larsson B, Pennert K, Rybo E, Sjöström L: Distribution of adipose tissue and risk of cardiovascular disease and death: a 12-year follow-up of participants in the population study of women in Gothenburg, Sweden. BMJ 1984;289:12571261.
25 Folsom AR, Kushi LH, Anderson KE, Mink PJ, Olson JE, Hong CP, Sellers TA, Lazovich D, Prineas RJ: Associations of general and abdominal obesity with multiple health outcomes in older women: the Iowa Women's Health Study. Arch Intern Med 2000;160: 2117-2128.

26 Tanko LB, Bagger YZ, Alexandersen P, Larsen PJ, Christiansen C: Peripheral adiposity exhibits an independent dominant antiatherogenic effect in elderly women. Circulation 2003;107:1626-1631.

27 Snijder MB, Dekker JM, Visser M, Bouter LM, Stehouwer CD, Yudkin JS, Heine RJ, Nijpels G, Seidell JC: Trunk fat and leg fat have independent and opposite associations with fasting and postload glucose levels: the Hoorn study. Diabetes Care 2004;27:372377.

28 Seidell JC, Perusse L, Despres JP, Bouchard C: Waist and hip circumferences have independent and opposite effects on cardiovascular disease risk factors: the Quebec Family Study. Am J Clin Nutr 2001;74:315-321.

$\checkmark 29$ Pasquali R: Obesity and androgens: facts and perspectives. Fertil Steril 2006;85:13191340

30 Tanko LB, Bruun JM, Alexandersen P, Bagger YZ, Richelsen B, Christiansen C, Larsen PJ: Novel associations between bioavailable estradiol and adipokines in elderly women with different phenotypes of obesity: implications for atherogenesis. Circulation 2004; 110:2246-2252.

31 Kalish GM, Barrett-Connor E, Laughlin GA, Gulanski BI: Association of endogenous sex hormones and IR among postmenopausal women: results from the Postmenopausal Estrogen/Progestin Intervention Trial. J Clin Endocrinol Metab 2003;88:1646-1652.

32 Han TS, Sattar N, Lean M: ABC of obesity: assessment of obesity and its clinical implications. BMJ 2006;333:695-698.

-33 Wang Y, Rimm EB, Stampfer MJ, Willett WC, Hu FB: Comparison of abdominal adiposity and overall obesity in predicting risk of type 2 diabetes among men. Am J Clin Nutr 2005;81:555-563.

34 Rimm EB, Stampfer MJ, Giovannucci E, Ascherio A, Spiegelman D, Colditz GA, Willett WC: Body size and fat distribution as predictors of coronary heart disease among middle-aged and older US men. Am J Epidemiol 1995; 141:1117-1127.

>35 Kragelund C, Omland T: A farewell to bodymass index? Lancet 2005;366:1589-1591.

-36 Abdella N, Khogali M, al-Ali S, Gumaa K, Bajaj J: Known type 2 diabetes mellitus among the Kuwaiti population: a prevalence study. Acta Diabetol 1996;33:145-149. 